\title{
Systemic mastocytosis with KIT V560G mutation presenting as recurrent episodes of vascular collapse: response to disodium cromoglycate and disease outcome
}

\author{
lolanda Conde-Fernandes ${ }^{1,2}$, Rita Sampaio ${ }^{3}$, Filipa Moreno ${ }^{3}$, José Palla-Garcia ${ }^{3}$, Maria dos Anjos Teixeira ${ }^{4,7}$, \\ Inês Freitas ${ }^{5,7}$, Esmeralda Neves ${ }^{6,7}$, Maria Jara-Acevedo ${ }^{8,9,10}$, Luis Escribano $0^{8,9,10}$ and Margarida Lima ${ }^{1,4,7^{*}}$ (D)
}

\begin{abstract}
Background: Mastocytosis are rare diseases characterized by an accumulation of clonal mast cells (MCs) in one or multiple organs or tissues. Patients with systemic mastocytosis (SM), whose MCs frequently arbor the activating D816V KIT mutation, may have indolent to aggressive diseases, and they may experience MC mediator related symptoms. Indolent SM with recurrent anaphylaxis or vascular collapse in the absence of skin lesions, ISMs(-), is a specific subtype indolent SM (ISM), and this clonal MC activation disorder represents a significant fraction of all MC activation syndromes. The V560G KIT mutation is extremely rare in patients with SM and its biological and prognostic impact remains unknown.
\end{abstract}

Case presentation: A 15-year old boy was referred to our hospital because of repeated episodes of flushing, hypotension and syncope since the age of 3-years, preceded by skin lesions compatible with mastocytosis on histopathology that had disappeared in the late-early childhood. Diagnosis of ISM, more precisely the ISMs(-) variant, was confirmed based on the clinical manifestations together with increased baseline serum tryptase levels and the presence of morphologically atypical, mature appearing (CD117+high, FceRI+) phenotypically aberrant (CD2+, CD25+) MCs, expressing activation-associated markers (CD63, CD69), in the bone marrow. Molecular genetic studies revealed the presence of the KITV560G mutation in bone marrow MCs, but not in other bone marrow cells, whereas the screening for mutations in codon 816 of KIT was negative. The patient was treated with oral disodium cromoglycate and the disease had a favorable outcome after an eleven-year follow-up period, during which progressively lower serum tryptase levels together with the fully disappearance of all clinical manifestations was observed.

Conclusions: To the best of our knowledge this first report of a patient with ISM, whose bone marrow MCs carry the KITV560G activating mutation, manifesting as recurrent spontaneous episodes of flushing and vascular collapse in the absence of skin lesions at the time of diagnosis, in whom disodium cromoglycate had led to long term clinical remission.

Keywords: Mast cells, Systemic mastocytosis, Mast cell activation disorders, Recurrent anaphylaxis, KITV560G mutation, Disodium cromoglycate

\footnotetext{
*Correspondence: mmc.lima@clix.pt

${ }^{4}$ Laboratório de Citometria, Serviço de Hematologia Clínica, Hospital de

Santo António (HSA), Centro Hospitalar do Porto (CHP), Ex-CICAP, Rua D.

Manuel II, s/n, 4099-001 Porto, Portugal

Full list of author information is available at the end of the article
} 


\section{Background}

Mastocytosis are rare diseases characterized by an accumulation of clonal mast cells (MCs) in one or multiple tissues, whose clinical manifestations mostly depend on the overall MC burden, the organs and/tissues involved, and the effects of the MC mediators such as histamine, leukotrienes, tryptase and heparin [1].

Criteria for the diagnosis and classification of mastocytosis were discussed extensively by the experts on the subject and consensus proposals were made in the last years $[2,3]$. These proposals were adopted by the World Health Organization (WHO) in 2001 [4] and 2008 [5], and lastly updated in 2016 [6]. The 2016 classification of the WHO divides the disease into cutaneous mastocytosis (CM), systemic mastocytosis (SM), and localized mast cell tumors $[6,7]$. Cutaneous mastocytosis includes maculopapular CM, also known as urticaria pigmentosa, diffuse CM, and localized mastocytoma of skin. Systemic mastocytosis is further divided into indolent SM, smoldering SM, and advanced SM variants, including aggressive SM, mast cell leukemia (MCL), and SM with associated hematologic neoplasm (SM-AHN), previously known as SM with associated clonal hematologic non-MC lineage disease (SM-AHNMD) [6, 7]. Other rare SM variants have been described so far, such as well-differentiated SM (WDSM) [8, 9] and ISM with recurrent anaphylaxis or vascular collapse in the absence of skin lesions, ISMs(-) [10].

The diagnosis of SM is based on the identification of neoplastic MCs by morphological, immunophenotypic, and genetic studies in organs and/or tissues outside the skin, including mostly the bone marrow (BM), and requires at least one major and one minor criteria, or three minor criteria [4-7]. The only major criterion of $\mathrm{SM}$ is the multifocal accumulation and clustering of $\mathrm{MC}$ (at least $15 \mathrm{MC}$ /cluster) in the $\mathrm{BM}$ or another extracutaneous organ. Minor criteria include an abnormal MC morphology, expression of CD2 and/or CD25 in MC in extracutaneous organs, an activating mutation in codon 816 of KIT (usually KIT D816V) in extra-cutaneous cells, and a basal serum tryptase level exceeding $20 \mathrm{ng} / \mathrm{ml}$. Monitoring of serum tryptase is useful both for the diagnosis and follow-up of the disease [11].

Indolent SM with recurrent anaphylaxis or vascular collapse in the absence of skin lesions, ISMs(-), is a specific subtype of clonal MC activation disorder (cMCAD) $[12,13]$, and represents a significant fraction of all MC activation syndromes (MCAS), a heterogeneous group of conditions in which the most prominent clinical manifestations result from the release of MC mediators [14, 15]. The European Competence Network on Mastocytosis (ECNM) classified MCAS into three major groups: primary (corresponding to $\mathrm{CMCAD}$ ), secondary (allergy related), and idiopathic (no clonal MCs and MCA triggers identified) [14]. Patients with cMCAD can be further subdivided into those fulfilling the WHO criteria for the diagnosis of SM and those satisfying only one or two minor criteria [14].

Recently, we reviewed the clinical and laboratory features of a series of adult patients with mastocytosis referred to and followed in a dedicated multidisciplinary consultation for mastocytosis in our center [16]. Here we describe in detail one of these patients with recurrent episodes of vascular collapse, who presented a rare KIT V560G activating mutation in bone marrow MCs, and had a very favorable outcome after a follow-up of 11-year, with a remarkable clinical and laboratory response to oral disodium cromoglycate (DSCG).

\section{Case report}

A 15 year-old Caucasian male was referenced to our institution in November 2005 for investigation of severe episodes of flushing, hypotension and vascular collapse since his late-early childhood; at that time, he referred a past history of several admissions at the emergency room for similar episodes. He had no history of urticaria, angioedema, and allergy or identified MCA triggers. In particular, the life-threatening episodes were not caused by food, medications, insect bites, temperature changes, exercise, or other recognized factors. Of note, the patient had been diagnosed with cutaneous mastocytosis at the age of 3-year, based on histopathological analysis of maculopapular skin lesions which disappeared soon thereafter. At the time of referral, he didn't have skin lesions, hepatomegaly, splenomegaly, or lymphadenopathy, and he was under $\mathrm{H} 1$ anti-histamines therapy, without the relief of the crises. Laboratory investigation showed markedly increased baseline serum tryptase levels ( $175 \mu \mathrm{g} / \mathrm{l}$; normal range: $2-13 \mu \mathrm{g} / \mathrm{l})$. Transient increase in serum tryptase above the baseline values during the MC-mediators related events were not documented, because blood samples for determination of serum tryptase levels were not taken at the episodes flushing, hypotension and vascular collapse. The BM aspirate was normocellular with increased numbers of MC (1.7\%), most of which had an atypical (type I) morphology (spindle-shaped MC with irregular distribution and focal accumulation of the cytoplasmic granules, and elongated cytoplasmic extensions); the myeloid/erythroid ratio was normal and there was no myelodysplasia (Fig. 1, panel A). The BM trephine (stained with hematoxylin-eosin and Giemsa), showed a normocellular BM without dysplastic features or increased blast cells, but a few scattered morphologically abnormal MCs, difficult to recognize (Fig. 1, panel B). Dense BM mast cell aggregates ( $>15$ cells/aggregate) were not observed. 


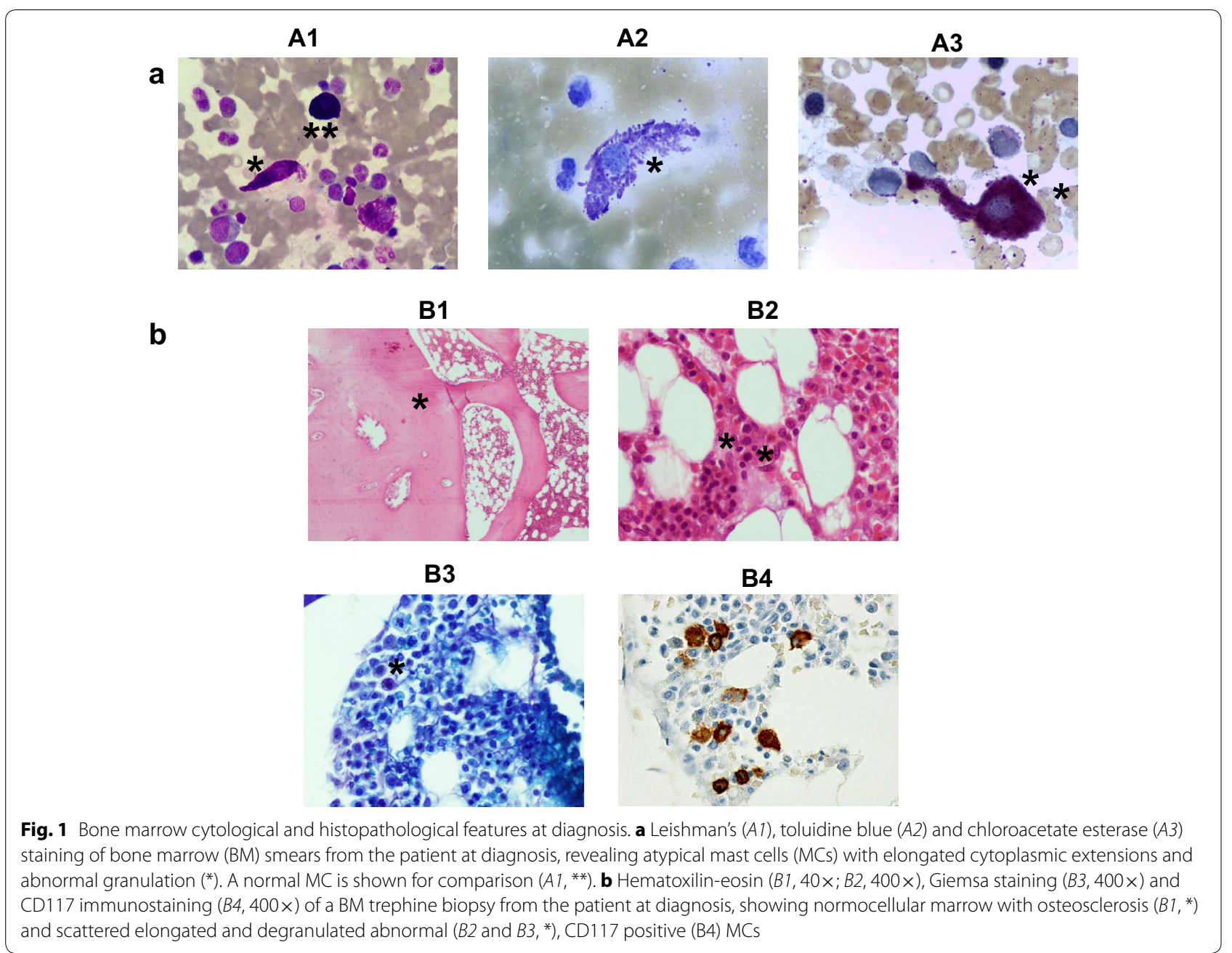

Flow cytometry confirmed the presence of BM mast cells with abnormally high light scatter values (SSC and FSC), and a mature (CD117+high, FceRI+high), but aberrant (CD2+, CD25+) and activated (CD63+high, CD69+high) phenotype (Fig. 2, panel A). Molecular analysis showed the absence of the KIT Asp-816(r)Val mutation; in contrast, the KIT Val-560(r)Gly activating mutation was detected in FACS-purified BM mast cells (Fig. 2, panel B), but not in other BM myeloid and lymphoid cells, including BM precursors. Serum IgE levels were within normal values $(7 \mathrm{KU} / \mathrm{l}$; normal levels $<100 \mathrm{KU} / \mathrm{l}$ ), and the screening for IgE antibodies specific for common food and inhalant allergens and Hymenoptera venom was negative. The remaining workup, which included a full blood cell count, biochemical tests, bone densitometry and abdominal ultrasound, was unremarkable. Thus, although the patient had no skin lesions since his late childhood, the case fulfilled the WHO criteria for the diagnosis of ISM. Based on these findings and on the clinical manifestations, the patient was diagnosed with the ISMs(-) variant $[12,13]$. H1 anti-histamines were maintained and oral DSCG (200 mg capsules, administered 5-times/day) was added. Since the start of DSCG therapy, systemic MC-associated symptoms have remained under control and serum tryptase levels progressively decreased over time, from $175 \mu \mathrm{g} / \mathrm{l}$ in November 2005 (first observation) to $61 \mu \mathrm{g} / \mathrm{l}$ in 2008, $49 \mu \mathrm{g} / \mathrm{l}$ in 2011, $45 \mu \mathrm{g} / \mathrm{l}$ in 2013, $31 \mu \mathrm{g} / \mathrm{l}$ in August 2015 and $35 \mu \mathrm{g} / \mathrm{l}$ in September 2016 (last observation). The patient is currently 26 years-old and he remains completely asymptomatic under DSCG therapy.

\section{Methods}

Serum tryptase levels were measured by using the UniCAP tryptase fluoroenzyme immunoassay (Pharmacia Diagnostics AB, Uppsala, Sweden). The presence of IgE antibodies to the mixtures of common inhalant and food allergens was screened with the ImmunoCAPT ${ }^{\mathrm{TM}}$ Phadiatop Infant ${ }^{\circledR}$ (Pharmacia Diagnostics AB, Uppsala, Sweden). 


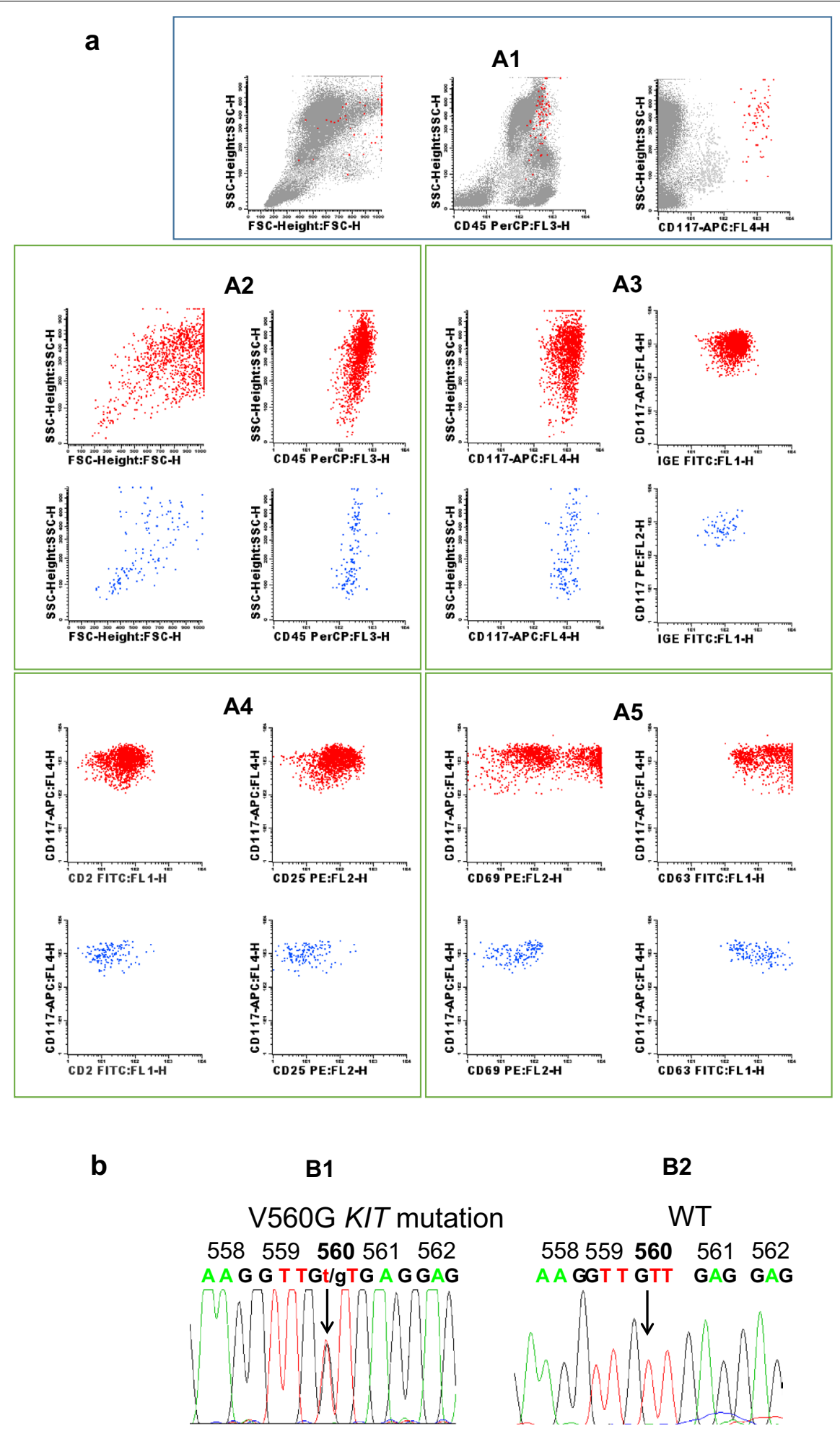

Fig. 2 Immunophenotypic and genetic features of bone marrow (BM) mast cells (MCs). a Illustrating bivariate dot-plots of the BM cells from the patient (panel A1), and after selecting specifically for BM mast cells (panels A2-A4); as illustrated, bone marrow MCs showed a mature (CD117+high, FceRl+high) (panel A2), aberrant (CD2+, CD25+) (panel A3) immunophenotype, with expression of activation-associated markers (CD63, CD69) in a large fraction of the cells (panel A4). Corresponding dot plots from normal bone marrow MCs (blue dots) are show for comparison. b Sequences of polymerase chain reaction (PCR) products illustrating the presence of the KITV560G mutation in bone marrow MCs from the patient, at diagnosis (panel B2); the wild-type (WT) sequence is shown for comparison 
Flow cytometry immunophenotyping of BM mast cells was performed using a stain-lyse-and-then-wash direct immunofluorescence technique (BD FACS Lysing Solution $^{\mathrm{TM}}$, Becton Dickinson Biosciences, BD, CA, USA), accordingly to the recommendations of the REMA [17]. Briefly, BM cells were stained with 4-color combinations of monoclonal antibodies directed against the CD45, CD117, CD2, CD25, CD63, CD69 and FceRI, conjugated with fluorescein isothiocyanate (FITC), phycoerythrin $(\mathrm{PE})$, peridinin chlorophyll protein (PerCP) or allophycocyanin (APC). Anti-CD45 (PerCP) and anti-CD117 (APC) were combined in different tubes with anti-IgE (FITC)+anti-CD33 (PE), anti-CD2 (FITC)+anti-CD25 (PE), or anti-CD63 (FITC)+anti-CD69 (PE). Data acquisition was performed in a FACSCalibur flow cytometer (BD), using the BD CellQuest ${ }^{\mathrm{TM}}$ software (BD). In the first step, 50,000 events from the whole BM cells were acquired per tube, and CD117+ high BM mast cells, were quantified. In the second step, acquisition though a live gate specifically drawn to include only BM mast cells was performed and only the events included in this region were stored. For data analysis, the Infinicyt ${ }^{\mathrm{TM}}$ software (version 17.0, Cytognos, Salamanca, Spain) was used. Mast cells were first identified based on their typical CD45+CD117+high phenotype and then characterized for the expression of other cell surface markers.

KIT mutations were detected in highly purified ( $>97 \%$ purity) BM cell populations as previously described in detail [18]. Positivity for the KIT V560G mutation was confirmed by sequencing the PCR products in both directions in an ABI Prism 3130 Genetic Analyzer (Applied Biosystems, Foster City, CA), using the $5^{\prime}$-CCA GAG TGC TCT AAT GAC TG-3 and 5-AGC CCC TGT TTC ATA CTG AC-3 primers (Isogen Life Sciences) and the dye-deoxy terminator method.

\section{Discussion}

The case here reported fulfills the WHO criteria for the diagnosis of SM, with three minor diagnostic criteria being present: increased baseline serum tryptase levels, morphologically atypical and phenotypically aberrant $(\mathrm{CD} 2+, \mathrm{CD} 25+)$ bone marrow MCs [6, 7]. However, in contrast to what is observed in most of the patients with ISM, the KIT D816V mutation was absent [19, 20]. Instead, the BM mast cells, but not other BM cells, were found to have the KIT V560G activating mutation. Interestingly, while skin lesions compatible with mastocytosis had occurred at the age of 3-year, they had regressed in the late-early childhood, the only disease-associated symptoms that persisted over time being recurrent episodes of flushing, hypotension and vascular collapse.

Clonal MC activation disorders comprise a heterogeneous group of conditions that do not always fulfil the
WHO criteria for SM; such conditions typically shave gain of function KIT mutations associated to constitutively activated MCs [12-15]. The clinical manifestations may vary in type and severity, and they usually include abdominal cramping, diarrhea, tachycardia, arrhythmias, irritability, and/or many other signals and symptoms related to the release of MC mediators. As it occurred in our patient, life-threatening episodes of anaphylaxis, including flushing, hypotension and vascular collapse, taking place spontaneously or after a Hymenoptera sting, may occur, particularly in patients who show no skin lesions typical of mastocytosis [12-15].

Systemic mastocytosis has been associated with the presence of somatic mutations in the v-kit Hardy-Zuckerman four feline sarcoma viral oncogene homolog (KIT), which encodes for a transmembrane protein stem cell receptor with kinase activity (KIT receptor, CD117) that binds to the stem cell factor (SCF) [21, 22]. Typically, in the majority $(>90 \%)$ of the ISM patients the A71763T substitution is detected at codon 816 in exon 17 of the KIT gene, whereby an aspartate is changed for a valine of the KIT protein sequence [21, 22]. However, other uncommon somatic (e.g., V560G, D815K, D816Y, D816F, D816H, and D820G) and germline (e.g., F522C, A533D, K509I and del419) mutations have been reported in a small number of cases [21,22]. Of note, this is the first case described so far in the literature who carried the KIT V560G activating mutation.

Two activating point mutations of KIT leading to two distinct amino acid substitutions in the KIT receptor, i.e. Asp-816(r)Val and Val-560(r)Gly, have been described in the MC leukemia cell line (HMC-1), derived from a patient with SM [21-23]. The D816V mutation affects the activating loop of the KIT receptor and occurs in $>90 \%$ of adult SM patients [18-21, 24], not only in the BM, but also in the peripheral blood $[18,25]$. In contrast, the V560G mutation involves the juxta membrane domain of the KIT receptor and is preferentially found in gastrointestinal stromal tumors, been reported in only a few SM cases [19, 20, 26-28] (Table 1). In this regard, it should be noted that despite the first description of the V560G $K I T$-mutation has been made decades ago, this mutation was not found in purified BM mast cells from a series of 113 adult patients diagnosed with SM at the reference centers of the Spanish Network on Mastocytosis (REMA) [19], published in 2006. Interestingly, however, it was subsequently described to be present in BM mast cells from 1 of 123 patients $(0.8 \%)$ in a subsequent update of the REMA 2006 series, published in 2010 [20]. In parallel, the KIT V560G mutation was found in the skin biopsy of only $1 \mathrm{CM}$ patient out of 142 adult patients diagnosed with mastocytosis at the reference centers of the French Mastocytosis Network (AFIRMM) [28], which 
Table 1 Frequency of KIT codon 816 and 560 mutations in patients with mastocytosis

\begin{tabular}{|c|c|c|c|c|c|}
\hline Reference & Büttner et al. [26] & Yanagihori et al. [27] & Garcia-Montero et al. [19] & Teodosio et al. [20] & Lanternier et al. [28] \\
\hline Country & Germany & Japan & Spain & Spain & France \\
\hline Number of patients studied & 17 & 16 & 113 & 123 & 142 \\
\hline Adults/children & $6 / 11$ & $12 / 4$ & $113 / 0$ & $123 / 0$ & $142 / 0$ \\
\hline Males/females & NA & $12 / 4$ & $58 / 55$ & $66 / 57$ & $43 / 93$ \\
\hline $\mathrm{CM} / \mathrm{SM}$ & $17(100 \%) / 0(0 \%)$ & $16(100 \%) / 0(0 \%)$ & $0(0 \%) / 113(100 \%)$ & $0(0 \%) / 123(100 \%)$ & $38(27 \%) / 104(73 \%)$ \\
\hline Adult/childhood onset & $6(35 \%) / 11(65 \%)$ & $4(25 \%) / 12(75 \%)$ & NA/NA & NA/NA & $114(80 \%) / 28(20 \%)$ \\
\hline Sample types tested & Skin & Skin & Bone marrow & Bone marrow & Skin \\
\hline Cell types tested & All cells & All cells & Mast cells & Mast cells & All cells \\
\hline KIT codon 816 mutations & $6 / 17(35 \%)$ & $14 / 16(88 \%)$ & $102 / 113(90 \%)$ & $93 / 123(6 \%)$ & $97 / 138(70 \%)$ \\
\hline Adult onset & $6 / 6(100 \%)$ & $4 / 4(100 \%)$ & NA & NA & $86 / 112(77 \%)$ \\
\hline Children onset & $0 / 11(0 \%)$ & $10 / 12(83 \%)$ & NA & NA & $11 / 26(42 \%)$ \\
\hline KIT codon 560 mutations & $2 / 6(33 \%)$ & $0 / 16(0 \%)$ & $0 / 113(0 \%)$ & $1 / 123(0.8 \%)$ & $1 / 138(0.7 \%)$ \\
\hline Adult onset & $2 / 4(50 \%)$ & $0 / 4(0 \%)$ & NA & NA & $1 / 112(0.9 \%)$ \\
\hline Children onset & 0/2 (0\%) & $0 / 12(0 \%)$ & NA & NA & $0 / 26(0 \%)$ \\
\hline
\end{tabular}

CM cutaneous mastocytosis, SM systemic mastocytosis, NA not available

confirms that this is a rare but recurrent KIT mutation in mastocytosis.

Previous studies have emphasized the relevance of performing molecular studies in purified BM mast cells, as well as in other BM cells, such as CD34+ precursors and mature myeloid and lymphoid BM cells to search not only for the KIT D816V mutation, but also for other KIT mutations, particularly if the BM mast cells have an aberrant immunophenotype and/or abnormal morphological features $[19,20]$. In accordance, Garcia-Montero et al. [19] have showed the presence of KIT D816V mutation in virtually all adults $(93 \%)$ with SM, while other KIT mutations were rarely $(<3 \%)$ detected. In addition, they demonstrated that in around one-third of patients with SM, the KIT mutation was detected not only in MC, but also in CD34+ hematopoietic cells and eosinophils, and, to a lesser extent, in monocytic and neutrophil-lineage BM precursor cells and lymphocytes [19]. Furthermore, they found that most patient with poor-prognosis SM (81\%) carried the KIT mutation in two or more BM myeloid cell populations, while this occurred in a smaller proportion (27\%) of indolent SM cases [19]. Moreover, a number of studies have suggested that "atypical" (non D816V) KIT mutations may facilitate transformation to more advanced MC disease [7]; however, the prognostic value of the KIT V560G activating mutation is not established, due to its rarity. Additional mutations in other genes (e.g., TET2, SRSF2, ASXL1, CBL, RUNX1, and RAS, and less commonly, JAK2 V617F and RUNX1-RUNX1T1) may occur in patients suffering from aggressive SM, MCL or SM-AHN, ASM, or MCL [7].

The activating KIT D816V and V560G mutations, despite targeting the same receptor, have a distinct impact on downstream signaling pathways, at the same time they might potentially be targeted by different tyrosine kinase inhibitors (TKI) [23]. Thus, the Janus kinase 3/signal transducer and activator of transcription (JAK3/STAT) pathway is the preferred signaling pathway involved in the KIT V560G mutation, whereas the mammalian target of rapamycin complex $1 / 4 \mathrm{E}$-binding protein 1 (mTORC1/4E-BP1) pathway is preferentially linked to the KIT D816V mutation [23].

The KIT D816V mutation, which is found in the majority of patients with SM and initiates a number of signal transduction events, is thought to trigger abnormal MC activation. However, not all patients with KIT $\mathrm{D} 816 \mathrm{~V}+\mathrm{SM}$ suffer from MC activation symptoms, suggesting that other mechanism may be implicated. Unfortunately, till recently the only in vitro model available for studying the impact of KIT mutations on human MC biology was the HMC-1 cell line, which arbor the KIT V560G mutation. Two sublines of HMC-1 were subsequently described, named HMC-1.1 (KIT V560G+) and HMC-1.2 (KIT V560G+, KIT D816V+) [29]. However, the fact that both HMC-1 sublines contain the KIT V560G mutation, whereas only the HMC-1.2 subline exhibits the KIT D816V mutation, makes it difficult to compare the signaling pathways activated by each of the mutant forms of KIT. To overcome these limitations, Saleh et al. [30] have recently established a KIT D816V+ SCF-independent MC line (ROSAKIT D816V), for which a KIT SCF-dependent wild type (ROSAKIT WT) exists. They found that ROSAKIT D816V cells produce a MC tumors in mice models, but, unexpectedly, ROSAKIT D816V cells exhibited a decreased responsiveness to IgEdependent stimuli as compared to ROSAKIT WT cells, and mice with ROSAKIT D816V-derived MC tumors 
did not show $\mathrm{MC}$ mediator-related symptoms. In addition, they realized that KIT $\mathrm{D} 816 \mathrm{~V}+\mathrm{MC}$ obtained from patients with SM did not show increased IgE-dependent histamine release. They concluded that KIT D816V mutation does not activate $\mathrm{MC}$ to release proinflammatory mediators, and they proposed that $\mathrm{MC}$ mediator-related symptoms in patients with SM occur preferentially in the context of a coexisting allergy [30]. Our patient, whose BM mast cells harbor the KIT V560G mutation, had MCmediator related events without clinical or laboratory evidence of allergy, as documented by normal serum IgE levels and negative screening for IgE antibodies specific for food and inhalant allergens. Thus, it would be of interest to explore whether KIT V560G promotes, instead of suppressing, IgE-mediated histamine release.

Overall, three distinct MC immunophenotypic profiles (mature, activated and immature) were described so for patients with SM, which correspond to different disease subtypes, namely WDSM, ISM/cMCAD and ASM/ MCL, respectively [20]. So, BM mast cells from patients with ISM and cMCAD have a high light scatter, a mature (CD117+high, FceRI+high), activated (overexpression of CD63, CD69, CD203c, and other activation related markers) and aberrant (CD25+, CD2+) phenotype, as found in this case.

Symptomatic treatment of SM is mainly based on avoidance of factors triggering the release of MC mediators and may also include $\mathrm{H} 1$ and $\mathrm{H} 2$ anti-histamines, proton pump inhibitors, anti-leukotrienes, anti-cholinergic, corticosteroids, DSCG, and/or epinephrine in case of anaphylactic episodes. In aggressive SM, treatment with interferon alpha, cladribine (2-chlorodeoxyadenosine) or TKIs should to be considered. Concerning TKIs, imatinib mesylate is effective only in patients who do not carry the KIT D816V mutation or other exon 17 mutations [31]. The patient here reported, showing limited tumor burden and life-threatening episodes of vascular collapse, required only symptomatic therapy.

Cromoglicic acid (also known as cromoglycate or cromolyn), which is marketed as a sodium salt (disodium cromoglycate, DSCG, or cromolyn sodium), belongs to the group of chromones and is a mast cell stabilizer that prevents the release of $\mathrm{MC}$ mediators [32, 33]. Its mechanism of action remains poorly understood [32, 33]. DSCG has minimal systemic absorption following ingestion and negligible fat solubility, suggesting an inability to enter the cells and an interaction with a cell surface receptor $[32,33]$. In permeabilized mast cells, DSCG inhibits GTP-gamma-S-induced secretion by a mechanism not involving the nucleoside diphosphate kinase [34]. In activated neutrophils DSCG selectively inhibits $\mathrm{O}^{2}$-generation but not degranulation and such effect may be related with inhibition of assembly of an active NADPH oxidase and prevention of oxygen radical-induced tissue damage [35]. Inhibition of MC-mediated immediate-type hypersensitivity by DSCG has also been reported [36]. In addition, DSCG was found to be a G-protein-coupled receptor 35 agonist [37]. However, the exact biochemical basis of the response of MC carrying activating KIT mutations to DSCG are not known and it would be interesting to investigate if the KIT receptor itself or downstream signaling pathway components may serve as targets for this MC stabilizer.

Disodium cromoglycate is available as nasal spray (for allergic rhinitis), eye drops (for allergic conjunctivitis), and oral forms (capsules and aqueous solution, used to treat urticaria, ulcerative colitis, and mastocytosis), although availability varies from one country to another. Cromolyn sodium, capsules $(100 \mathrm{mg})$ and oral solution concentrate $(100 \mathrm{mg} / 5 \mathrm{ml})$, was approved by the Food and Drug Administration for the treatment of mastocytosis in adults and children aged more than 2 years-old, being licensed for that in the United States (capsules and ampules) and in Canada (capsules). In that concerning the effectiveness of DSCG in treatment of mastocytosis, the randomized controlled trials performed are scarce (we have found only four studies published in journals indexed in MedLine), historic (reported from 1979 to 1990), and small (enrolling 5-13 patients/trial); they have used variable doses of DSCG (200 mg taken orally four times daily in most cases) in different formulations (capsules, tablets or oral aqueous solution) and the results obtained were not totally concordant [38-41]. In the late 70 s, a double-blind crossover study of the efficacy of oral DSCG was carried out in 5 patients with SM for periods of 8-32 months; the authors observed that DSCG (but not placebo) produced marked amelioration of the pruritus, flushing, diarrhea, abdominal pain and disorders of cognitive function [38]. In the 90s, a double-blind, placebo-controlled trial of the efficacy of oral DSCG was conducted in 11 patients with SM; this study showed that DSCG was significantly helpful relative to placebo in alleviating the gastrointestinal manifestations, whereas the benefit for non-gastrointestinal symptoms did not reach statistical significance [39]. In between these studies, two other trials were published. In one of them, 13 patients ( 3 children and 10 adults) with mastocytosis having cutaneous and systemic symptoms participated in a blind trial and were treated for 1 month with placebo and for another month with oral DSCG; it was found that most patients experienced amelioration of the pruritus, improvement in urtication and relief of gastrointestinal manifestations when treated with DSCG [40]. The other study compared the efficacy of oral DSCG and combined $\mathrm{H} 1$ and $\mathrm{H} 2$ antihistamines [41]. In this study, 8 patients with SM were randomly assigned to receive 
either DSCG + placebo or antihistamines + placebo, with crossover at the end of week 10, and only 6 patients completed the study; although the differences between the two treatments were not statistically significant, the authors noted that most patients had less pruritus and less urticaria while receiving antihistamines, while most patients had improvement of the gastrointestinal symptoms and one patient experienced dramatic relief from bone pain while receiving DSCG [41]. In addition, case reports and small series of patients have stated benefits in using oral and topical DSCG for the treatment of diffuse cutaneous/bullous mastocytosis [42-44]. Moreover, oral and inhaled DSCG have been used in the management of other symptoms associated with SM, such as of bone pain, headache and fatigue, and hypotensive crisis $[45,46]$. Despite the low level of evidence found in the literature, DSCG is one of the mainstays in the symptomatic treatment of SM, being recommended by the experts from centers where a large number of patients with mastocytosis are followed, to alleviate gastrointestinal, cutaneous, neuropsychiatric, skeletal and other systemic disease related symptoms [47-49].

In Portugal, DSCG is not approved for the treatment of mastocytosis and the drug is not available in oral formulations. Our patient was treated off-label with manipulated gelatinous capsules containing 200 mg DSCG; as described, this therapeutic approach successfully abrogated the clinical manifestations related to the release of MC mediators, and might therefore be a non-toxic treatment option for this very small and unique subset of SM patients. Because childhood onset mastocytosis often regresses spontaneously by puberty, the possibility of the disappearance of the clinical manifestations in our patient being due to spontaneous regression of the disease with the advancing age cannot be completely excluded. However, this hypothesis seems improbable: first, when the patient was first observed in our consultation he had already 15 years old and he still had very high basal serum tryptase levels (13 times the upper limit of normal) and frequent episodes of flushing, hypotension and vascular collapse; second, there was a clear relationship between the beginning of DSCG treatment and the control of the clinical manifestations, with no such episodes being observed thereafter. In addition, although basal serum tryptase levels have declined steadily over the years after starting DSCG therapy, they were still increased at the last observation (2.6 times the upper limit of normal), indicating that the disease remains active, although clinically controlled.

In summary, here we described a young patient with SM whose the BM mast cells were found to harbor the activating KIT V560G mutation, in association with a mature, activated, and aberrant phenotype, who showed a sustained complete response of MC activation-associated life-threatening symptoms with long term therapy with DSCG.

\section{Conclusions}

Patients with SM, whose MCs frequently arbor the activating D816V KIT mutation, may have indolent to aggressive diseases, and they may experience diverse types of MC mediator symptoms. In contrast, the V560G mutation, which uses different signaling pathways to promote $\mathrm{MC}$ growth, is extremely rare and its biological and prognostic impact remains unknown. Here we reported a patient with recurrent spontaneous episodes of severe flushing and vascular collapse, who harbor the V560G KIT mutation in mature activated aberrant BM mast cells, in whom DSCG treatment had led to long term clinical remission.

\section{Abbreviations}

AFIRMM: French Mastocytosis Network; APC: allophycocyanin; ASM: aggressive systemic mastocytosis; BD: Becton-Dickinson; BM: bone marrow; CM: cutaneous mastocytosis; DSCG: disodium cromoglycate; CMCAD: clonal mast cell activation disorder; ECNM: European Competence Network on Mastocytosis; FITC: fluorescein isothiocyanate; ISM: indolent systemic mastocytosis; ISMs(-): indolent systemic mastocytosis without skin involvement (associated with recurrent anaphylaxis or vascular collapse); JAK3/STAT: Janus kinase 3/ signal transducer and activator of transcription; KIT: v-kit Hardy-Zuckerman 4 feline sarcoma viral oncogene homolog; MC: mast cell; MCAS: mast cell activation syndrome; MCL: mast cell leukemia; mTORC1/4E-BP: mammalian target of rapamycin complex 1/4e-binding protein 1; PE: phycoerythrin; PerCP: peridinin chlorophyll protein; REMA: Spanish Network on Mastocytosis; SCF: stem cell factor; SM: systemic mastocytosis; SM-AHNMD: systemic mastocytosis with an associated clonal hematological non-mast cell disorder; TKI: tyrosine kinase inhibitor; WDSM: well-differentiated systemic mastocytosis; WHO: World Health Organization.

\section{Authors' contributions}

ICF data collection and manuscript writing. RS, FM and JPG analysis of the bone marrow biopsy. MAT flow cytometry data analysis. IF analysis of the bone marrow aspirate. EN immunological studies. MJA cell sorting and molecular studies. LE case discussion and critical review of the manuscript. ML flow cytometry data analysis, clinical support, therapeutic decisions and manuscript writing. All authors discussed the final version of the manuscript. All authors read and approved the final manuscript.

\section{Authors' information}

lolanda Conde-Fernandes is dermatologist and has special interest in the clinical management of patients with mastocytosis.

Rita Sampaio, Filipa Moreno and José Palla-Garcia are junior medical doctors, undertaking training in Pathology, who manifested a special interest in the histopathological criteria for the diagnosis of mastocytosis.

Maria dos Anjos Teixeira is a senior medical doctor, consultant in Immunohemotherapy, with expertise in mast cell immunophenotyping.

Maria Inês Freitas and Esmeralda Neves are senior medical doctors, specialists in Clinical Pathology, with skills in cytological and immunological studies, respectively

Maria Jara-Acevedo is an expert in biotechnology, molecular biology and cancer research, including mast cell disorders.

Luis Escribano is a senior medical doctor, hematologist and an expert in mastocytosis. He was the promoter and founder of the Spanish Network on Mastocytosis (REMA), as part of the ECMN (European Competence Network on Mastocytosis). In addition, he established a center of excellence of the ECNM in the Instituto de Estudios de Mastocitosis de Castilla-La Mancha, Hospital Virgen del Valle, Toledo, Spain. 
Margarida Lima is a senior medical doctor, consultant in Immunohemotherapy, head of the flow cytometry hematology laboratory of the Hospital de Santo António, Centro Hospitalar do Porto, Porto, Portugal, and responsible for the multidisciplinary consultation on cutaneous lymphomas and mastocytosis at the same hospital. She is an expert in flow cytometry applied to the diagnosis of hemato-oncological disorders, especially those originating from $T$ cells, NK cells and mast cells, as well as in the clinical management of patients with cutaneous lymphomas and mastocytosis.

\begin{abstract}
Author details
${ }^{1}$ Consulta Multidisciplinar de Linfomas Cutâneos e Mastocitoses (CMLC), Hospital de Santo António (HSA), Centro Hospitalar do Porto (CHP), Porto, Portugal. ${ }^{2}$ Serviço de Dermatologia, Hospital de Santo António (HSA), Centro Hospitalar do Porto (CHP), Porto, Portugal. ${ }^{3}$ Serviço de Anatomia Patológica, Hospital de Santo António (HSA), Centro Hospitalar do Porto (CHP), Porto, Portugal. ${ }^{4}$ Laboratório de Citometria, Serviço de Hematologia Clínica, Hospital de Santo António (HSA), Centro Hospitalar do Porto (CHP), Ex-CICAP, Rua D. Manuel II, s/n, 4099-001 Porto, Portugal. ${ }^{5}$ Serviço de Hematologia Laboratorial, Hospital de Santo António (HSA), Centro Hospitalar do Porto (CHP), Porto, Portugal. ${ }^{6}$ Serviço de Imunologia, Hospital de Santo António (HSA), Centro Hospitalar do Porto (CHP), Porto, Portugal. ${ }^{7}$ Unidade Multidisciplinar de Investigação Biomédica, Instituto de Ciências Biomédicas da Universidade do Porto (UMIB/ICBAS/UP), Porto, Portugal. ${ }^{8}$ Servicio General de Citometría, Instituto de Biología Molecular y Celular del Cáncer, Centro de Investigación del Cáncer, Salamanca, Spain. ${ }_{9}^{9}$ Departamento de Medicina, Universidad de Salamanca (IBMCC-CSIC/USAL), Salamanca, Spain. ${ }^{10}$ Spanish Network on Mastocytosis (REMA), Toledo, Spain.
\end{abstract}

\section{Acknowledgements}

The authors thank to Prof. Alberto Orfao (Servicio General de Citometría, Instituto de Biología Molecular y Celular del Cáncer, Centro de Investigación del Cáncer and Departamento de Medicina, Universidad de Salamanca, IBMCCCSIC/USAL), Salamanca, Spain, and REMA, for consulting, laboratorial support, clinical advice and expert opinion.

\section{Competing interests}

The authors declare that they have no competing interests.

\section{Ethics approval and consent to publish}

The patient gave informed consent for publication of this case report and the accompanying images. Off-label prescription of disodium cromoglycate was performed after obtaining authorization of the Ethical Committee and the Pharmaceutical Committee of the Hospital.

\section{Publisher's Note}

Springer Nature remains neutral with regard to jurisdictional claims in published maps and institutional affiliations.

Received: 5 October 2016 Accepted: 6 April 2017

Published online: 24 April 2017

\section{References}

1. Quintás-Cardama A, Jain N, Verstovsek S. Advances and controversies in the diagnosis, pathogenesis, and treatment of systemic mastocytosis. Cancer. 2011;117:5439-49. doi:10.1002/cncr.26256.

2. Valent P, Horny HP, Escribano L, Longley BJ, Li CY, Schwartz LB, Marone G, Nuñez R, Akin C, Sotlar K, Sperr WR, Wolff K, Brunning RD, Parwaresch RM, Austen KF, Lennert K, Metcalfe DD, Vardiman JW, Bennett JM. Diagnostic criteria and classification of mastocytosis: a consensus proposal. Leuk Res. 2001;25:603-25. doi:10.1016/S0145-2126(01)00038-8.

3. Valent P, Akin C, Escribano L, Födinger M, Hartmann K, Brockow K, Castells M, Sperr WR, Kluin-Nelemans HC, Hamdy NA, Lortholary O, Robyn J, van Doormaal J, Sotlar K, Hauswirth AW, Arock M, Hermine O, Hellmann A, Triggiani M, Niedoszytko M, Schwartz LB, Orfao A, Horny HP, Metcalfe DD. Standards and standardization in mastocytosis: consensus statements on diagnostics, treatment recommendations and response criteria. Eur J Clin Investig. 2007;37:435-53. doi:10.1111/j.1365-2362.2007.01807.x.
4. Valent P, Horny H-P, Li CY, Longley JB, Metcalfe DD, Parwaresch RM, et al. Mastocytosis (mast cell disease). In: Jaffe ES, Harris NL, Stein H, Vardiman JW, editors. World Health Organization (WHO) classification of tumours. Pathology and genetics. Tumours of haematopoietic and lymphoid tissues. Lyon: IARC Press; 2001. p. 291-302.

5. Horny HP, Akin C, Metcalfe DD, Escribano L, Bennett JM, Valent P, et al. Mastocytosis (mast cell disease). In: Swerdlow SH, Campo E, Harris NL, Jaffe ES, Pileri SA, Stein H, et al., editors. World Health Organization (WHO) classification of tumours. Pathology and genetics. Tumours of haematopoietic and lymphoid tissues. Lyon: IARC Press; 2008. p. 54-63.

6. Horny HP, Akin C, Arber D, Peterson LA, Tefferi A, Metcalfe DD, et al. Mastocytosis. In: Swerdlow SH, Campo E, Harris NL, Jaffe ES, Pileri SA, Stein H, et al., editors. World Health Organization (WHO) classification of tumours. Pathology and genetics. Tumours of haematopoietic and lymphoid tissues. Lyon: IARC Press; 2016.

7. Valent P, Akin C, Hartmann K, Nilsson G, Reiter A, Hermine O, Sotlar K, Sperr WR, Escribano L, George TI, Kluin-Nelemans HC, Ustun C, Triggiani M, Brockow K, Gotlib J, Orfao A, Schwartz LB, Broesby-Olsen S, Bindslev-Jensen C, Kovanen PT, Galli SJ, Austen KF, Arber DA, Horny HP, Arock M, Metcalfe DD. Advances in the classification and treatment of mastocytosis: current status and outlook toward the future. Cancer Res. 2017;77:1261-70. doi:10.1158/0008-5472.CAN-16-2234.

8. Akin C, Fumo G, Yavuz AS, Lipsky PE, Neckers L, Metcalfe DD. A novel form of mastocytosis associated with a transmembrane c-kit mutation and response to imatinib. Blood. 2004;103:3222-5. doi:10.1182/ blood-2003-11-3816.

9. Álvarez-Twose I, Jara-Acevedo M, Morgado JM, García-Montero A, Sánchez-Muñoz L, Teodósio C, Matito A, Mayado A, Caldas C, Mollejo M, Orfao A, Escribano L. Clinical, immunophenotypic, and molecular characteristics of well-differentiated systemic mastocytosis. J Allergy Clin Immunol. 2015. doi:10.1016/j.jaci.2015.05.008.

10. Álvarez-Twose I, González de Olano D, Sánchez-Muñoz L, Matito A, Esteban-López MI, Vega A, Mateo MB, de Durana ADMD, de la Hoz B, Del Pozo Gil MD, Caballero T, Rosado A, Sánchez Matas I, Teodósio C, JaraAcevedo M, Mollejo M, García-Montero A, Orfao A, Escribano L. Clinical, biological, and molecular characteristics of clonal mast cell disorders presenting with systemic mast cell activation symptoms. J Allergy Clin Immunol. 2010;125(1269-78):e2. doi:10.1016/j.jaci.2010.02.019.

11. Matito A, Morgado JM, Álvarez-Twose I, Sánchez-Muñoz L, Pedreira CE, Jara-Acevedo M, Teodosio C, Sánchez-López P, Fernández-Núñez E, Moreno-Borque R, García-Montero A, Orfao A, Escribano L. Serum tryptase monitoring in indolent systemic mastocytosis: association with disease features and patient outcome. PLOS ONE. 2013;8:e76116. doi:10.1371/journal.pone.0076116.

12. Matito A, Alvarez-Twose I, Morgado JM, Sánchez-Muñoz L, Orfao A, Escribano L. Anaphylaxis as a clinical manifestation of clonal mast cell disorders. Curr Allergy Asthma Rep. 2014;14:450. doi:10.1007/ s11882-014-0450-8.

13. Gülen T, Hägglund H, Sander B, Dahlén B, Nilsson G. The presence of mast cell clonality in patients with unexplained anaphylaxis. Clin Exp Allergy. 2014:44:1179-87. doi:10.1111/cea.12369.

14. Valent P. Mast cell activation syndromes: definition and classification. Allergy. 2013;68:417-24. doi:10.1111/all.12126.

15. Petra Al, Panagiotidou S, Stewart JM, Conti P, Theoharides TC. Spectrum of mast cell activation disorders. Expert Rev Clin Immunol. 2014;10:729-39. doi:10.1586/1744666X.2014.906302.

16. Fernandes IC, dos Teixeira MA, Freitas I, Selores M, Alves R, Lima M. Adult mastocytosis: a review of the Santo António Hospital's experience and an evaluation of World Health Organization criteria for the diagnosis of systemic disease. An Bras Dermatol. 2014;89:59-66. doi:10.1590/ abd1806-4841.20141847.

17. Escribano L, Diaz-Agustin B, López A, Núñez López R, García-Montero A, Almeida J, Prados A, Angulo M, Herrero S, Orfao A. Spanish Network on Mastocytosis (REMA). Immunophenotypic analysis of mast cells in mastocytosis: when and how to do it. Proposals of the Spanish Network on Mastocytosis (REMA). Cytometry B Clin Cytom. 2004;58:1-8. doi:10.1002/cyto.b.10072.

18. Jara-Acevedo M, Teodosio C, Sanchez-Muñoz L, Álvarez-Twose I, Mayado A, Caldas C, Matito A, Morgado JM, Muñoz-González Jl, Escribano L, Garcia-Montero AC, Orfao A. Detection of the KIT D816V mutation in peripheral blood of systemic mastocytosis: diagnostic implications. Mod Pathol. 2015;28:1138-49. doi:10.1038/modpathol.2015.72. 
19. Garcia-Montero AC, Jara-Acevedo M, Teodosio C, Sanchez ML, Nunez R, Prados A, Aldanondo I, Sanchez L, Dominguez M, Botana LM, SanchezJimenez F, Sotlar K, Almeida J, Escribano L, Orfao A. KIT mutation in mast cells and other bone marrow hematopoietic cell lineages in systemic mast cell disorders: a prospective study of the Spanish Network on Mastocytosis (REMA) in a series of 113 patients. Blood. 2006;108:2366-72. doi:10.1182/blood-2006-04-015545.

20. Teodosio C, García-Montero AC, Jara-Acevedo M, Sánchez-Muñoz L, Alvarez-Twose I, Núñez R, Schwartz LB, Walls AF, Escribano L, Orfao A. Mast cells from different molecular and prognostic subtypes of systemic mastocytosis display distinct immunophenotypes. J Allergy Clin Immunol. 2010;125:719-26. doi:10.1016/j.jaci.2009.10.020.

21. Akin C. Clonality and molecular pathogenesis of mastocytosis. Acta Haematol. 2005;114:61-9. doi:10.1159/000085563.

22. Orfao A, Garcia-Montero AC, Sanchez L. Escribano L; REMA. Recent advances in the understanding of mastocytosis: the role of KIT mutations. Br J Haematol. 2007;138:12-30. doi:10.1111/j.1365-2141.2007.06619.x.

23. Chan IJ, Kasprowicz S, Tharp MD. Distinct signalling pathways for mutated KIT(V560G) and KIT(D816V) in mastocytosis. Clin Exp Dermatol. 2013;38:538-44. doi:10.1111/ced.12000.

24. Valent $P$, Akin C, Sperr WR, Mayerhofer M, Födinger M, Fritsche-Polanz R, Sotlar K, Escribano L, Arock M, Horny HP, Metcalfe DD. Mastocytosis: pathology, genetics, and current options for therapy. Leuk Lymphoma. 2005:46:35-48. doi:10.1080/10428190400010775.

25. Arock M, Sotlar K, Akin C, Broesby-Olsen S, Hoermann G, Escribano L, Kristensen TK, Kluin-Nelemans HC, Hermine O, Dubreuil P, Sperr WR, Hartmann K, Gotlib J, Cross NC, Haferlach T, Garcia-Montero A, Orfao A, Schwaab J, Triggiani M, Horny HP, Metcalfe DD, Reiter A, Valent P. KIT mutation analysis in mast cell neoplasms: recommendations of the European Competence Network on Mastocytosis. Leukemia. 2015;29:122332. doi:10.1038/leu.2015.24.Review.

26. Büttner C, Henz BM, Welker P, Sepp NT, Grabbe J. Identification of activating c-kit mutations in adult-, but not in childhood-onset indolent mastocytosis: a possible explanation for divergent clinical behavior. J Invest Dermatol. 1998;111:1227-31. doi:10.1046/j.1523-1747.1998.00414.x.

27. Yanagihori H, Oyama N, Nakamura K, Kaneko F. c-kit Mutations in patients with childhood-onset mastocytosis and genotype-phenotype correlation. J Mol Diagn. 2005;7:252-7. doi:10.1016/S1525-1578(10)60552-1.

28. Lanternier F, Cohen-Akenine A, Palmerini F, Feger F, Yang Y, Zermati Y, Barète S, Sans B, Baude C, Ghez D, Suarez F, Delarue R, Casassus P, Bodemer C, Catteau A, Soppelsa F, Hanssens K, Arock M, Sobol H, Fraitag S, Canioni D, Moussy A, Launay JM, Dubreuil P, Hermine O, Lortholary O, AFIRMM network. Phenotypic and genotypic characteristics of mastocytosis according to the age of onset. PLoS ONE. 2008;3:e1906. doi:10.1371/ journal.pone.0001906.

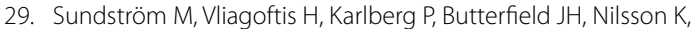
Metcalfe DD, Nilsson G. Functional and phenotypic studies of two variants of a human mast cell line with a distinct set of mutations in the c-kit proto-oncogene. Immunology. 2003;108:89-97. doi:10.1046/j.1365-2567.2003.01559.x.

30. Saleh R, Wedeh G, Herrmann H, Bibi S, Cerny-Reiterer S, Sadovnik I, Blatt K, Hadzijusufovic E, Jeanningros S, Blanc C, Legarff-Tavernier M, Chapiro E, Nguyen-Khac F, Subra F, Bonnemye P, Dubreuil P, Desplat V, MerleBéral H, Willmann M, Rülicke T, Valent P, Arock M. A new human mast cell line expressing a functional IgE receptor converts to tumorigenic growth by KIT D816V transfection. Blood. 2014;124:111-20. doi:10.1182/ blood-2013-10-534685.

31. Pardanani A. Systemic mastocytosis in adults: 2015 update on diagnosis, risk stratification, and management. Am J Hematol. 2015;90:250-62. doi:10.1002/ajh.23931.
32. Zhang T, Finn DF, Barlow JW, Walsh JJ. Mast cell stabilisers. Eur J Pharmacol. 2016;778:158-68. doi:10.1016/j.ejphar.2015.05.071.

33. Edwards AM, Holgate ST. The Chromones Cromolyn Sodium and Nedocromil Sodium. In: Adkinson NF, editor. Middleton's Allergy Principles and Practice, vol 2, section H. 8th ed. Philadelphia: Elsevier/Saunders; 2014. p. 1567-77.

34. Martin MW, O'Sullivan AJ, Gomperts BD. Inhibition by cromoglycate and some flavonoids of nucleoside diphosphate kinase and of exocytosis from permeabilized mast cells. Br J Pharmacol. 1995;115:1080-6. doi:10.1111/j.1476-5381.1995.tb15921.x.

35. Kilpatrick LE, Jakabovics E, McCawley LJ, Kane LH, Korchak HM. Cromolyn inhibits assembly of the NADPH oxidase and superoxide anion generation by human neutrophils. J Immunol. 1995;154:3429-36.

36. Shin HY, Kim JS, An NH, Park RK, Kim HM. Effect of disodium cromoglycate on mast cell-mediated immediate-type allergic reactions. Life Sci. 2004;74:2877-87. doi:10.1016/j.lfs.2003.10.026.

37. Yang Y, Lu JY, Wu X, Summer S, Whoriskey J, Saris C, Reagan JD. G-protein-coupled receptor 35 is a target of the asthma drugs cromolyn disodium and nedocromil sodium. Pharmacology. 2010;86:1-5. doi:10.1159/000314164.

38. Soter NA, Austen KF, Wasserman SI. Oral disodium cromoglycate in the treatment of systemic mastocytosis. N Engl J Med. 1979;301:465-9. doi:10.1056/NEJM197908303010903.

39. Horan RF, Sheffer AL, Austen KF. Cromolyn sodium in the management of systemic mastocytosis. J Allergy Clin Immunol. 1990;85:852-5. doi:10.1016/0091-6749(90)90067-E.

40. Czarnetzki BM, Behrendt H. Urticaria pigmentosa: clinical picture and response to oral disodium cromoglycate. Br J Dermatol. 1981;105:563-7. doi:10.1111/j.1365-2133.1981.tb00800.x.

41. Frieri M, Alling DW, Metcalfe DD. Comparison of the therapeutic efficacy of cromolyn sodium with that of combined chlorpheniramine and cimetidine in systemic mastocytosis. Results of a double-blind clinical trial. Am Med. 1985;78:9-14. doi:10.1016/0002-9343(85)90454-1.

42. Welch EA, Alper JC, Bogaars H, Farrell DS. Treatment of bullous mastocytosis with disodium cromoglycate. J Am Acad Dermatol. 1983;9:349-53.

43. Edwards AM, Capková S. Oral and topical sodium cromoglicate in the treatment of diffuse cutaneous mastocytosis in an infant. BMJ Case Rep. 2011. doi:10.1136/bcr.02.2011.3910.

44. Selva Folch B, López Almaraz R, Sánchez González R, de Las Martinez, Heras B. Diffuse cutaneous mastocytosis. Presentation of 3 cases and therapeutic management review. An Pediatr. 2016;84:286-8. doi:10.1016/j.anpedi.2015.07.003.

45. Edwards AM, Hagberg H. Oral and inhaled sodium cromoglicate in the management of systemic mastocytosis: a case report. J Med Case Rep. 2010;4:193. doi:10.1186/1752-1947-4-193.

46. Edwards A. A 38 year old woman with hypotensive shock at the onset of menstruation: case outcome. BMJ. 2009;338:b247. doi:10.1136/bmj.b247.

47. Escribano L, Akin C, Castells M, Schwartz LB. Current options in the treatment of mast cell mediator-related symptoms in mastocytosis. Inflamm Allergy Drug Targets. 2006;5:61-77. doi:10.2174/187152806775269303.

48. Arock M, Akin C, Hermine O, Valent P. Current treatment options in patients with mastocytosis: status in 2015 and future perspectives. Eur J Haematol. 2015;94:474-90. doi:10.1111/ejh.12544.

49. González-de-Olano D, Matito A, Orfao A, Escribano L. Advances in the understanding and clinical management of mastocytosis and clonal mast cell activation syndromes. F1000Res. 2016:5:2666. doi:10.12688/ f1000research.9565.1. 